\title{
Friction reducing performance of carbon nanotubes covered pistons in internal combustion engines - engine test results
}

This article discusses the posibility of reducing friction losses in internal combustion engines by using carbon nanotubes, pointing out the large potential of this application. Experimental pistons were made of standard aluminum alloy and coated with a layer of nanotube deposits by spraying them with an aqueous solution containing the binder. The proposed technology of applying layers of nanotubes can be adopted in industrial-scale production. Engine tests were carried out showing a significant reduction of the engine motoring torque, up to $16 \%$ for the experimental pistons, thus confirming the favorable tribological properties of nanotubes observed in tribological research and reported by many authors. Supplementary tests were carried out: SEM, EDS, coordinate measuring technique, and $x$-ray tomography. An alternative technology for hierarchical nanotube multilayer coatings electro-deposition was proposed.

Key words: combustion engines, piston, carbon nanotubes, friction

\section{Introduction}

\subsection{Significance of friction losses in internal combustion} engine and the ways to reduce it

There are currently about 1 billion cars in use worldwide, the vast majority of them are powered with piston engines. Tens of millions of new cars are manufactured around the globe every year, also among these cars a great majority is still powered by piston engines. A popular opinion in recent years is the mistaken belief that car emissions are a major source of environmental pollution and a major cause of the greenhouse effect, and that the solution to this is to replace the internal combustion engine with an electric one. In fact, the use of electric cars makes sense only in the centers of large cities where emission problems are not successfully controlled.

Well-to-wheel analysis has shown that even if there were a breakthrough in the construction of the battery in the near future, wide use of electric motors in car powertrains would have a negative net carbon dioxide emissions balance $[6,39]$. The solution to this issue would be a radical increase in the share of renewable energy sources in global electricity production, but this task would take decades to achieve.

Contemporary conditions mean that efforts to make the internal combustion engines more environmentally friendly and powerful are the most important. The overall efficiency of the modern automobile engine reaches $45 \%$, but only for medium speed and high load conditions. In these operating conditions the friction loss contribution in the total energy balance of the engine is small, which is expressed by the mechanical efficiency exceeding 90\%. Unfortunately, in normal operation the car engine works most of the time at small and very small load conditions, and then the friction loss plays a dominant role in the overall energy balance. The most frequent operating condition of the internal combustion engine is one where the actual power is very small in comparison to the engine's maximum power, but still all the engine components are kept in motion, and thus produce a frictional force similar to that produced under high load. Mechanical efficiency of the engine in the NEDC test and under normal operation of the vehicle is significantly less than $50 \%$, thus becoming the main factor determining the low overall efficiency of the engine. This is a wellknown problem where direct methods of approach, based on reduction of friction losses, have already been widely exploited $[18,41]$ leaving very little scope for further improvement.

Another, indirect and more effective way to reduce friction losses is to replace a large engine with a smaller one, usually with lower number of cylinders, and to compensate the power deficit through the application of turbocharging. This concept is called "downsizing" [17] and has been successfully implemented for most car engines produced in Europe in the last 10 years. The higher the degree of downsizing, the greater the benefits in terms of improving the efficiency and reducing fuel consumption. The barrier is the increasing mechanical and thermal load of the engine structure, which can be controlled by the use of new materials with properties superior to the conventional materials used to date [17].

In the opinion of the authors, the next step in the process of improving the design of internal combustion engines can be the application of nanomaterials. Carbon nanotubes (CNT) are a relatively recently discovered and intensively studied material [4, 11]; among their unique features extremely beneficial tribological properties are often mentioned $[8,22]$.

\subsection{Results of atomic scale carbon nanotube research}

The authors expect that the use of CNTs in the design of internal combustion engines may reduce friction loss and fuel consumption. Furthermore, CNTs can allow for increasing the permissible normal load in sliding contact, e.g. on the piston skirt. This can allow for shifting the border of downsizing and may be an indirect but very effective ap- 
proach to increase the overall efficiency and reduce fuel consumption of vehicle engines. Checking the validity of the above hypothesis requires multi-stage research, with special emphasis on engine tests. These are pioneering studies and the authors do not know of any international publications which contain results of similar studies

The literature presents numerous papers whose experimental work consisted of determining the friction coefficient of CNTs by the method of simulation of dynamic processes on the atomic scale [31, 38, 44]. The friction and adhesion phenomena, in relation to a single CNT, were also the subject of research conducted using atomic force microscopes (AFM) [9, 15, 30].

The work carried out independently in a number of research groups has led to determining the coefficients of friction that differ by two orders of magnitude or more. Adhesion occurring at the atomic level makes it difficult to extrapolate the results of research conducted for single CNTs on the surfaces of macroscopic size. The results of the research of friction processes in the microscopic scale, however, allow for clarification of the following information for the engine tests:

- the friction force of CNTs is largely dependent on the direction of movement relative to their axis

- an increase in temperature increases the thermal motions of atoms and in the atomic scale leads to increased friction force

- the diameter of the CNT does not substantially affect the value of the friction force

- the friction force increases with the speed of the CNT movement relative to the substrate

- atoms of non-carbon elements attached to the outer surface of the CNTs can greatly reduce the friction force; the use of fluoride [42] can reduce the coefficient of friction by $0.002-0.070$.

Due to the relatively weak interaction between the opposite walls in multi-walled carbon nanotubes (MWCNTs), solely resulting from van der Waals forces, they are deformable. The deformations are elastic and reversible, and the CNTs are not destroyed in the process, due to the strong covalent bonds between adjacent carbon atoms. In the studies discussed in [37] single-wall and multi-wall nanotubes were subjected to loads in the plane perpendicular to their axis. A linear dependence of strength and deformation was found, which allowed for the determination of the Young's modulus. For single-wall carbon nanotubes (SWCNTs) a modulus of $810 \pm 410 \mathrm{GPa}$ was obtained, while for MWCNTs with a diameter of $26 \mathrm{~nm}$ to $76 \mathrm{~nm}$, it was 1.28 $\pm 0.59 \mathrm{TPa}$. In the same study it was found that the mechanical properties obtained in the catalytic synthesis of MWCNTs strongly depend on their structure. The resiliency of the atomic structure of the CNT may be used for the covering layer of the piston skirt to dampen the forces caused by lateral motion of the piston.

\subsection{Research of layers formed from carbon nanotubes performed outside the engine}

The laboratory research of layers of CNTs obtained by the catalytic synthesis on the surface of silicon carbide is documented in the literature [3]. The surface of the substrate was sprayed with nickel nanoparticles which consti- tute a catalyst for the synthesis of CNTs. This synthesis was plasma-assisted, and the choice of plasma parameters enabled the shaping of adhesive properties in obtained layers. The tribological testing was performed using a ball pressed against a rotating plate, in a vacuum and in moist air. The results show the benefits of the strong bond between the layers of CNTs and the parent material. The lowest friction coefficient of less than 0.1 was obtained for layers with high adhesion, which did not undergo mechanical destruction. Furthermore, it was observed that in order to reduce friction, it is desirable to use layers of CNTs with a high order parameter.

A later, independent project [1] synthesized CNTs of ordered parallel structure on the sample surface of stainless steel. In one of the experiment series an intermediate layer of cobalt was used, resulting in more compact growth of CNTs and strongly favorable tribological properties.

Although the research results shown did not include the use of oil or any other lubricant, the information formulated on the basis of these results may be useful in understanding the phenomena of the boundary lubricating regime on the piston skirt.

The subject of the research presented in [40] was the vibration damping properties of epoxy resin containing carbon fibers, on the surface of which CNTs have been synthesized. CNTs entangling the carbon fibers led to a substantial increase in contact area with the resin, and enabled a significant improvement in the damping properties of the composite. The damping and energy dissipation, the authors explained, is the result of the friction occurring between the resin and CNTs. Presented composites [27, 40] may serve as an inspiration to create layers to replace the graphite piston skirt coating. Similar materials are already used in commercially produced friction bearings $[2,34,36]$.

In parallel to the research into resins described above, works are also carried out in order to create CNT reinforced composites based on aluminum. This is usually achieved by using powder metallurgy; CNTs are mixed with metal powder, sintered and subjected to an extrusion process [25]. The technique is time-consuming, costly and difficult to use in high-volume production of engine pistons. The alternative is a modification of the piston surface material, which may include the introduction of CNTs into the aluminum alloy in the friction stir process. A description of such a successful experiment can be found in [21, 28, 29], where at the same time the resistance of the SWCNTs to high temperature that occurs temporarily during the friction process was confirmed.

\section{Materials and methods}

\subsection{Research concept}

Particularly preferential tribological properties of carbon nanotubes reported in microscopic scale studies using AFM were confirmed also in relation to the macroscopic surface properties studied in a tribometer. The aim of the research presented in this article was to verify whether carbon nanotubes deposited on the piston skirt can effectively contribute to the reduction of internal combustion engine friction losses. 
The authors conducted their most extensive studies of CNT covered pistons using the original test stand built as part of a doctoral thesis [24] and described in detail later in the monograph [23]. Due to its design the constructed test stand allows the simulation of research conditions closer to the complete working engine than a classic tribometer. This test stand is used to measure the sum of friction losses in the piston assembly and the crankshaft bearings in conditions similar to those prevailing in an operating engine.

The concept of the study is a comparison of the motoring torque of engine mounted with the standard pistons with the corresponding values for engine with the experimental pistons coated with a layer of MWCNTs on the skirt.

Directly after installing the experimental pistons in the engine preliminary test lasting 100 minutes was performed at a constant oil temperature of $80^{\circ} \mathrm{C}$ and at a constant speed of $1000 \mathrm{rpm}$, while monitoring the torque. The purpose of this initial test was the rejection of pistons, which did not provide stable working conditions.

Both for the reference pistons and the experimental pistons fundamental tests were performed for 96 operating points of the engine at a wide range of oil temperatures $\left(50^{\circ} \mathrm{C}, 80^{\circ} \mathrm{C}\right.$ and $\left.110^{\circ} \mathrm{C}\right)$, rotational speeds of the crankshaft (set in steps of $250 \mathrm{rpm}$ starting at $500 \mathrm{rpm}$ up to $3000 \mathrm{rpm}$ ) and load, simulated by changing the air pressure for the cylinder supply ( 0 bar, 1 bar and 1.5 bar).

The experimental pistons which passed through all the stages of engine research had a total engine running time of about 10 hours.

\subsection{Experimental pistons}

Experimental pistons were made by the NanoLab Inc. company using a procedure developed by that company. Experimental pistons were prepared by covering the skirt surface of the standard aluminum pistons with a layer of industrial grade MWCNTs of diameter around $15 \mathrm{~nm}$, and the of length in the range $5 \ldots .20 \mu \mathrm{m}$. The solution was prepared from four constituents: $100 \mathrm{ml}$ of distilled water, 300 $\mathrm{mg}$ of dodecylbenzensulfonic acid (DBS), $300 \mathrm{mg}$ of MWCNT PD15L5-20, $5 \mathrm{ml}$ of potassium silicate solution (KASIL 1, 2.50 weight ratio potassium silicate, 29.1\% $\mathrm{K}_{4} \mathrm{SiO}_{4}$ solution in water. PQ Corporation, P.O. Box 840, Valley Forge, Pa. 19482, USA.) The distilled water, MWNCTs, and DBS were sonicated with a horn sonicator for $10 \mathrm{~min}$. The potassium silicate was then added, and the complete solution was stirred for $1 \mathrm{~min}$.

The aqueous solution of CNTs was applied in a number of successive passes by spraying onto the surface of the piston, which had been pre-heated to $95^{\circ} \mathrm{C}$. A few tens of milliliters of the solution were used to cover the skirt surface of a single piston. The process was finalized by keeping the piston at $300^{\circ} \mathrm{C}$ for $1 \mathrm{~h}$.

In order to develop the technology, many tests have been performed using cut parts of the piston and later with whole pistons. In total, tens of pistons were used, but only six of them were considered adequate to test in the engine, creating three sets of pistons for a two-cylinder engine. Finally, only one set of pistons (pistons labelled A2 and A3) successfully passed the preliminary engine test and was used in the fundamental friction tests. Figure 1 is a view of a standard aluminum piston used for the reference test and the final version of the experimental piston with a layer of CNTs on the side surface. The proposed coating of CNTs is the subject of extensive research as an alternative to the standard coatings of graphite or molybdenum [12-14, 26, 32].
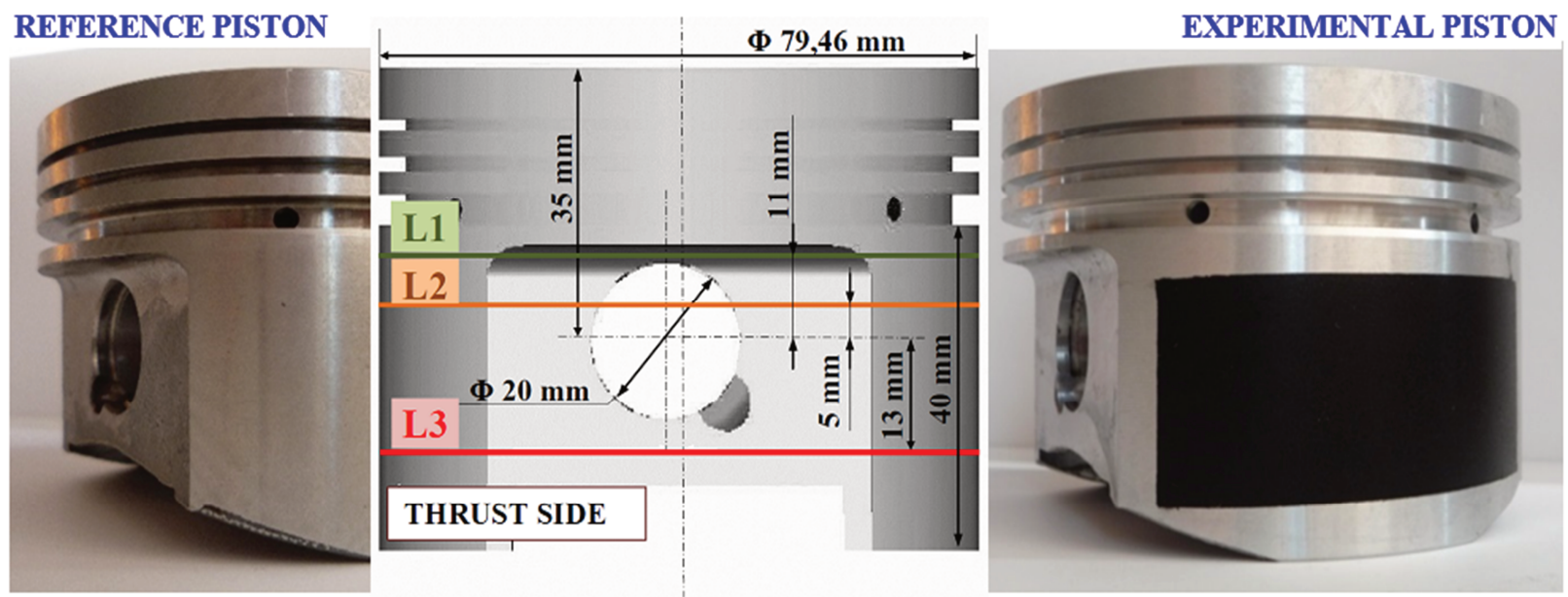

Fig. 1. The original piston made out of aluminum alloy, and an experimental piston coated with CNTs, showing horizontal levels L1-L3 determined for further assessment of wear

\subsection{Test bench}

The test bench (Fig. 2) consists of a modified twocylinder in-line internal combustion engine driven by an electric motor. The torque is transmitted through the shaft with an HBM type T5 torque meter of range $50 \mathrm{Nm}$, which enables accurate measurement of torque (the relative standard deviation of reproducibility declared by manufacturer according to DIN 1319 was as low as $\pm 0.025 \mathrm{Nm}$ ). The Spider 8 device produced by HBM was used for recording the measurement signal. Each of the torque values presented in this paper is an average calculated from 20,000 consecutive measurements recorded at a frequency of $9.6 \mathrm{kHz}$.

The engine camshaft is immobilized, leaving all valves in the closed position; the crankshaft-driven water and oil 
pumps were also immobilized and replaced with outside units, powered by individual electric motors. The applied changes meant that during each revolution of the crankshaft the piston forces compression and decompression of the load contained in the cylinder, while a portion of the cylinder load leaks into the crankcase. With the engine valves closed, blow-by gases can be countered by the use of additional one-way valves mounted in place of the spark plugs, and named load refill valves. The test bench design permits opening and closing of these valves to allow free air intake, either from the ambient air or of air supplied at a certain overpressure. Funneling more air into the cylinder at the beginning of the compression stroke under increased pressure causes an increase in the maximum cylinder pressure. This is a method to simulate increased load in a real engine.
A very important original feature is the system that maintains a constant oil temperature with an oil-engine cooling liquid heat exchanger, with a radiator, a heater and electrically powered coolant and oil pumps. The PID controller makes it possible to maintain the desired oil temperature with $\pm 0.2^{\circ} \mathrm{C}$ accuracy, ensuring the reproducibility of the measurements. For the standard engine configuration the deviation of the medium torque value in a series of 20000 standard recording data points never exceeded 0.05 $\mathrm{Nm}$. This was confirmed during the tests involving the same working conditions, performed independently at seven day intervals.

In comparative studies presented later in this article, a standard Castrol Edge engine oil with viscosity grade 5W/30 and quality class API SL was always used.
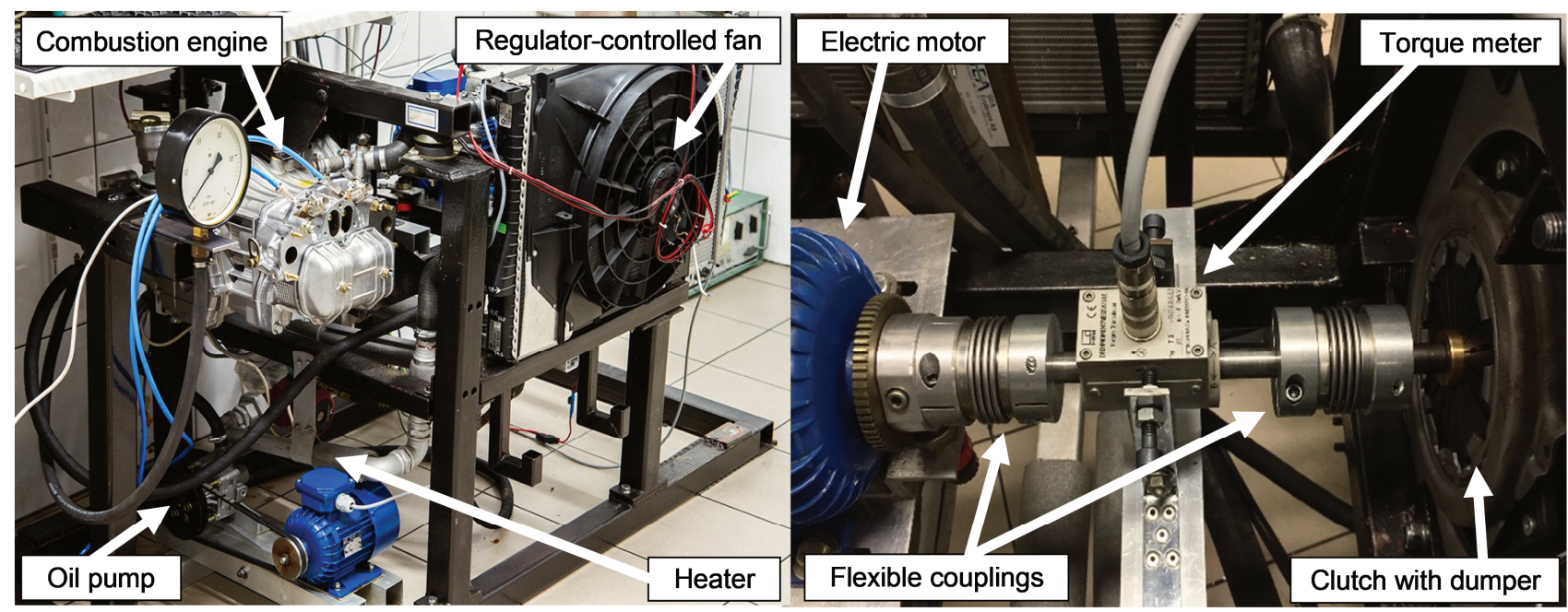

Fig. 2. The test bench for measuring the friction losses in the crank mechanism; general view on the left and a method for measuring the torque of the motoring torque on the right

\subsection{Piston surface characterization}

Studies of experimental engine pistons are preceded by a series of experiments designed to characterize the layer of carbon nanotubes; many of these studies were repeated after the engine test and removing the pistons from the engine.

- Testing the roughness of reference pistons surface, experimental pistons before application of CNTs, after application of CNTs, after the engine tests: Mahr Perthen Perthometer S8P profiler with a contact measuring tip RHT6-50 was used. Stylus tip radius was $5 \mu \mathrm{m}$ and the pressure force was $0.8 \ldots 1.2 \mathrm{mN}$.

- Examination of the surface shape of the reference and experimental pistons before the application of CNTs, after the application of CNTs and after engine tests: Coordinate measuring machine DEA Global Image 7.7.5. with the Renishaw SP25M probe head and SM25-2 module; measuring tip with a length of $62 \mathrm{~mm}$ and a measuring ball of diameter $6 \mathrm{~mm}$ was used.

- Formtester used for the measurement of the CNT layers' wear: Hommel etamic roundscan 535.

- Examining the shape of the cylinder walls before and after the tests, to determine the wear of cylinder running surfaces: digital bore gauge Mitutoyo 511-501.
- Computer tomography of the pistons in order to eliminate hidden defects in materials: GE v|tome|x s 240.

- Examining the CNT layer structure: SEM Mira 3 Tescan and Jeol JSM-7001F microscopes.

- EDS: Princeton Gamma-Tech, Inc.

\section{Results}

\subsection{Engine friction measurement}

Figure 3 shows a comparison of the results obtained in preliminary tests made on one of a test version of the pistons and the final version of the piston. Due to the clearly unstable behavior of the friction losses of the engine pistons with experimental pistons the test was discontinued, the test made for the final version of pistons was completed successfully. Due to the fact that the methodology of measurement in the preliminary test and the actual tests was identical, the obtained results may also be used to assess the reproducibility of the measurements.

Figure 4 shows a comparison between the motoring torque for the engine with the standard and experimental pistons A2 and A3. Each of the three graphs shows the torque registered over speed range for a defined oil temperature. Each point in Figure 4 was created by calculating the mean value of engine motoring torque, which was recorded 
for about two seconds. The example comparison of instantaneous engine motoring torque for reference and CNT covered pistons, registered at $500 \mathrm{rpm}$ and 50 Celsius degree of the oil temperature, is show in Fig. 5. For each temperature there were three series of tests, varying in terms of piston side load, resulting from the pressure of the air supplied to the cylinder. The oil temperature and cylinder supply air pressure are given in the description of the measurement series; the higher the air pressure, the higher the gas force and the resulting normal force pressing the piston against the cylinder wall.

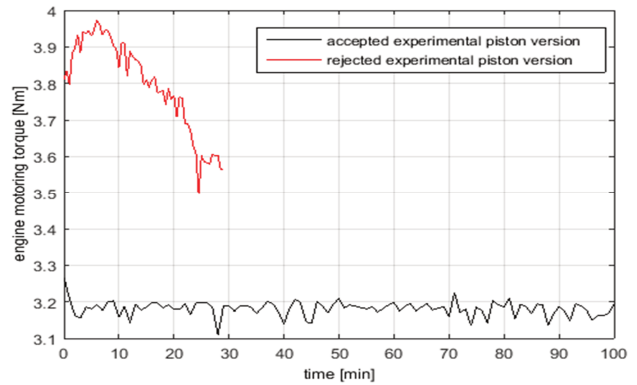

Fig. 3. Preliminary engine test of two CNT-coated experimental piston versions representing early and final development stages; comparing the stability of the engine motoring torque over time

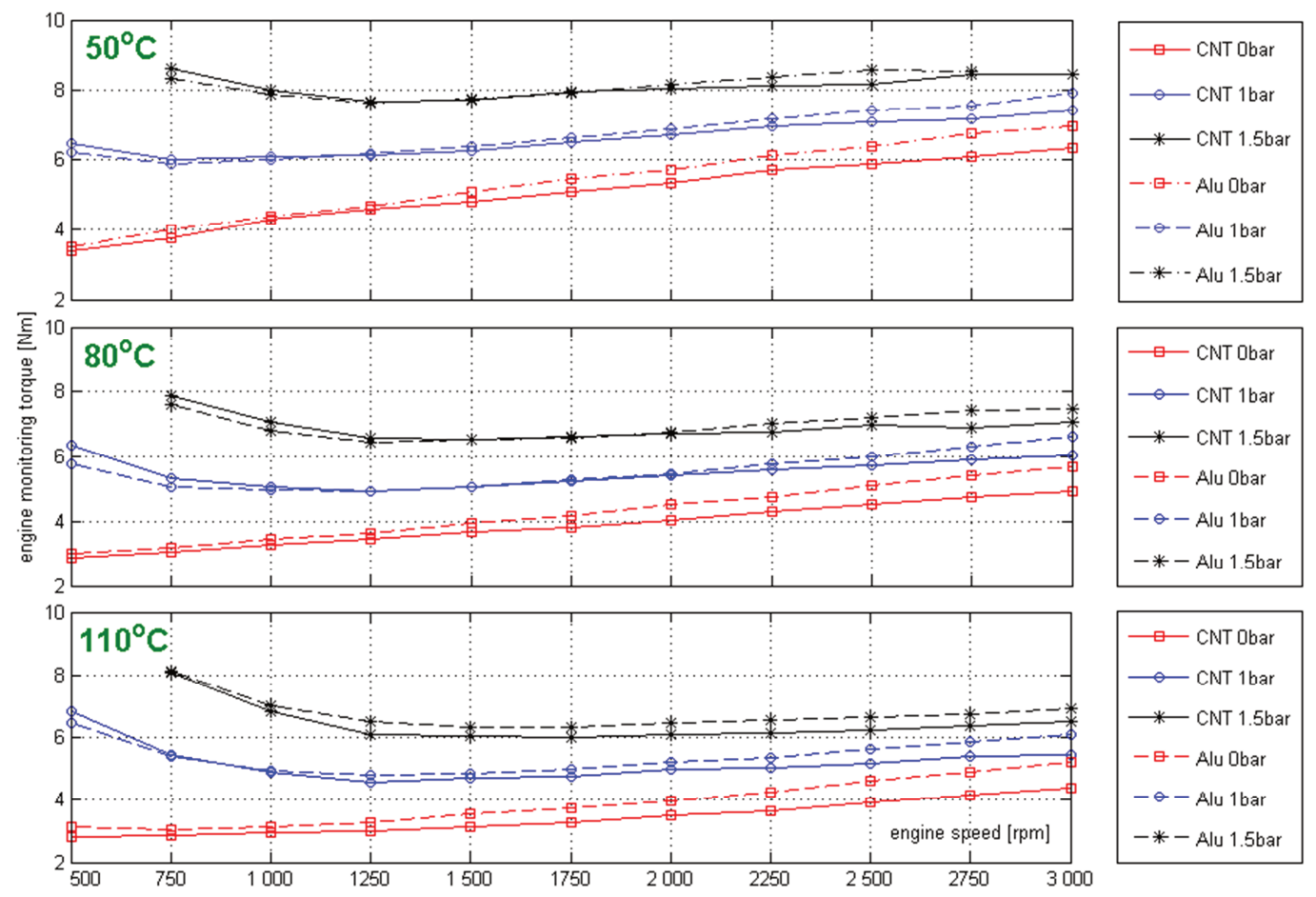

Fig. 4. Comparison of engine friction losses of standard aluminum pistons and pistons coated with CNTs, as a function of engine speed; results measured at different engine oil temperatures and cylinder supply pressures

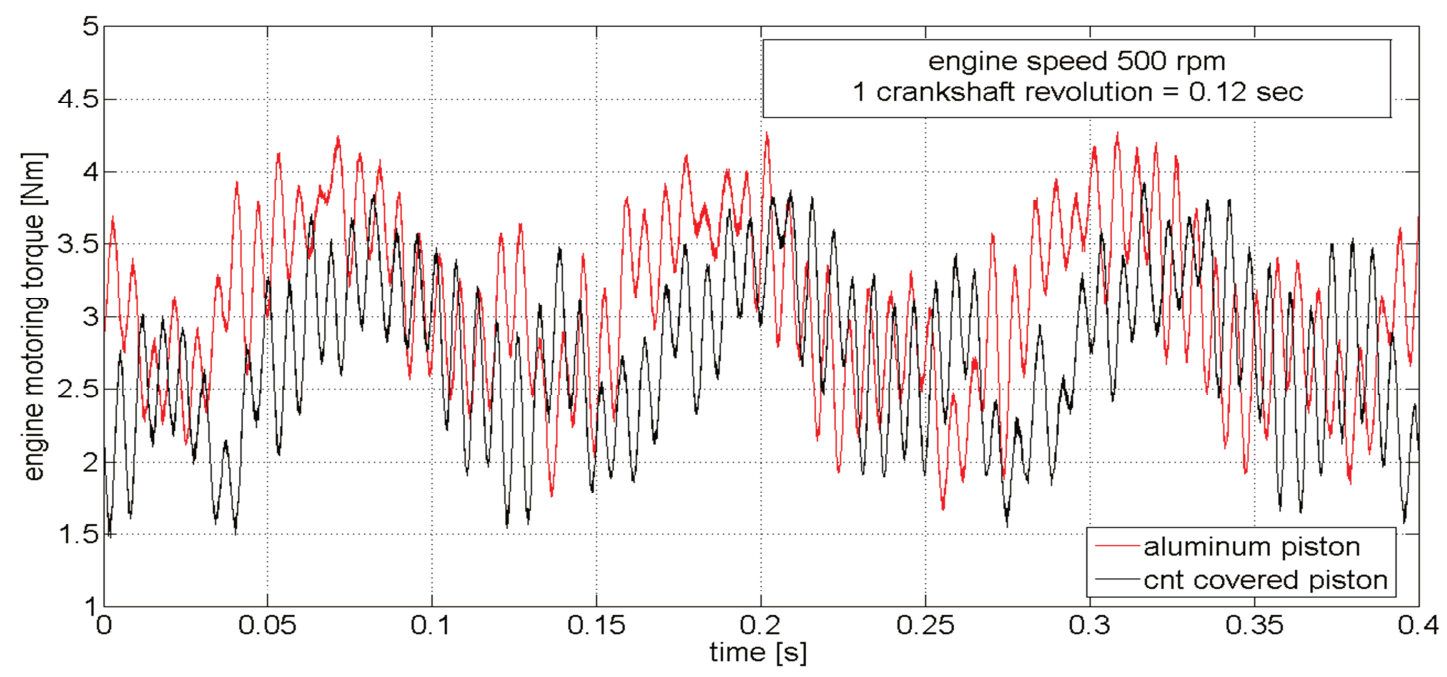

Fig. 5. Comparison of engine motoring torque raw signal for reference aluminum and CNT covered pistons 


\subsection{Characterization of the CNT layer on the experimental pistons}

After dismounting the experimental pistons from the engine, it was found that the adhesion of the layer of CNTs on the aluminum surface of the piston was sufficient and no layer peeling occurred. Signs of rubbing of the layer of CNTs on the cylinder wall could be seen by naked eye; the layer of CNTs had been clearly smoothed, but at no point was it scratched to reveal the aluminum surface. The intensity of the abrasion phenomenon of the layer of CNTs can be inferred from Fig. 6, which shows the results of measurement of the shape of the experimental piston skirt before mounting it in the engine and after the engine test. Indirectly, the wear on the CNT layer surface also shows a reduction in surface roughness during engine operation. Surface roughness was measured for each of the piston for six sections symmetrically located on the circumference, each measuring section had a length of about 12 $\mathrm{mm}$. The most characteristic surface profiles are shown in Fig. 7, an overview of the basic parameters is shown in Table 1.

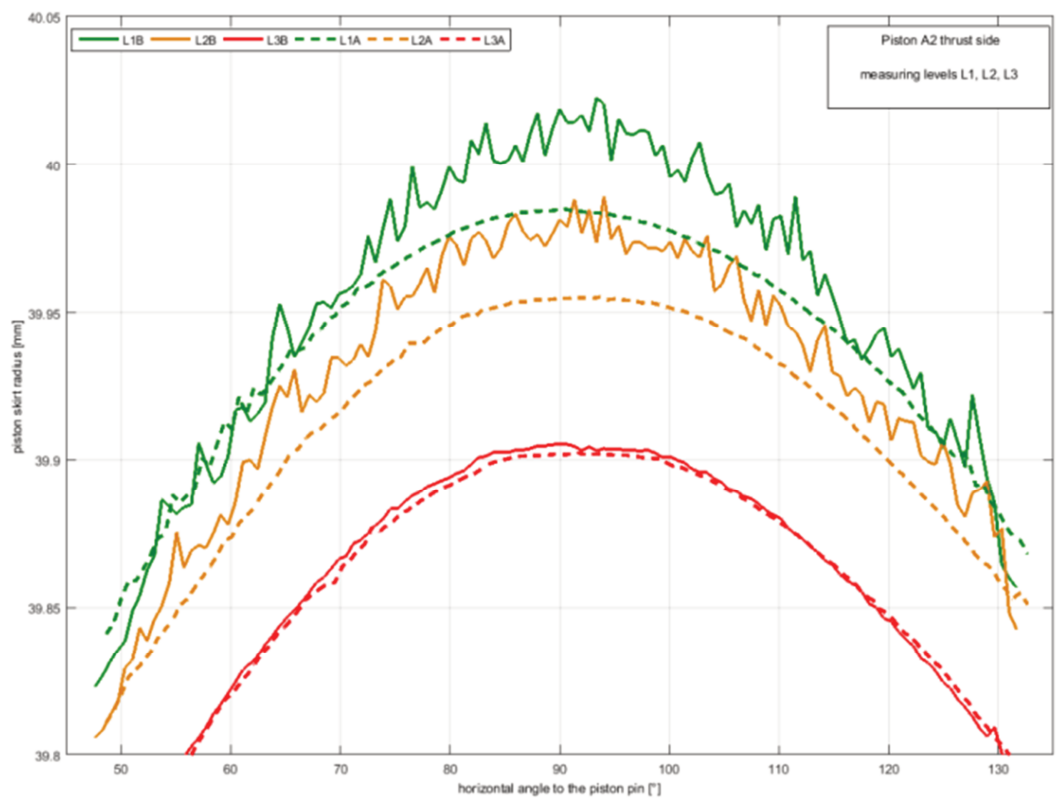

Fig. 6. The radius of the piston skirt coated with CNTs, measurements on the piston thrust side in horizontal levels L1, L2, L3. Results obtained with the coordinate measuring technique before installing the piston in the engine (solid line L1B, L2B, L3B) and after the engine test (dashed line L1A, L2A, L3A)

Table. 1. Parameters describing the surface roughness of tested pistons

\begin{tabular}{|c|c|c|c|c|c|c|c|}
\hline & & Reference & \multicolumn{5}{|c|}{ A2 and A3 Experimental (average values) } \\
\hline \multicolumn{2}{|c|}{ Research phase } & after engine tests & before applying CNTs & before engine tests & \multicolumn{3}{|c|}{ after engine tests } \\
\hline \multicolumn{2}{|c|}{ Measurement method } & mean & mean & mean & major thrust side & minor thrust side & mean after tests \\
\hline \multirow{4}{*}{ 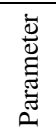 } & $\mathrm{Ra}$ & 3.99 & 3.39 & 4.72 & 3.33 & 4.18 & 3.75 \\
\hline & $\mathrm{Rq}$ & 4.57 & 3.95 & 5.78 & 3.80 & 4.85 & 4.33 \\
\hline & $\mathrm{Rt}$ & 15.57 & 16.91 & 38.41 & 17.42 & 24.21 & 20.82 \\
\hline & Rsk & -0.06 & 0.79 & 0.4 & 0.26 & 0.23 & 0.24 \\
\hline
\end{tabular}
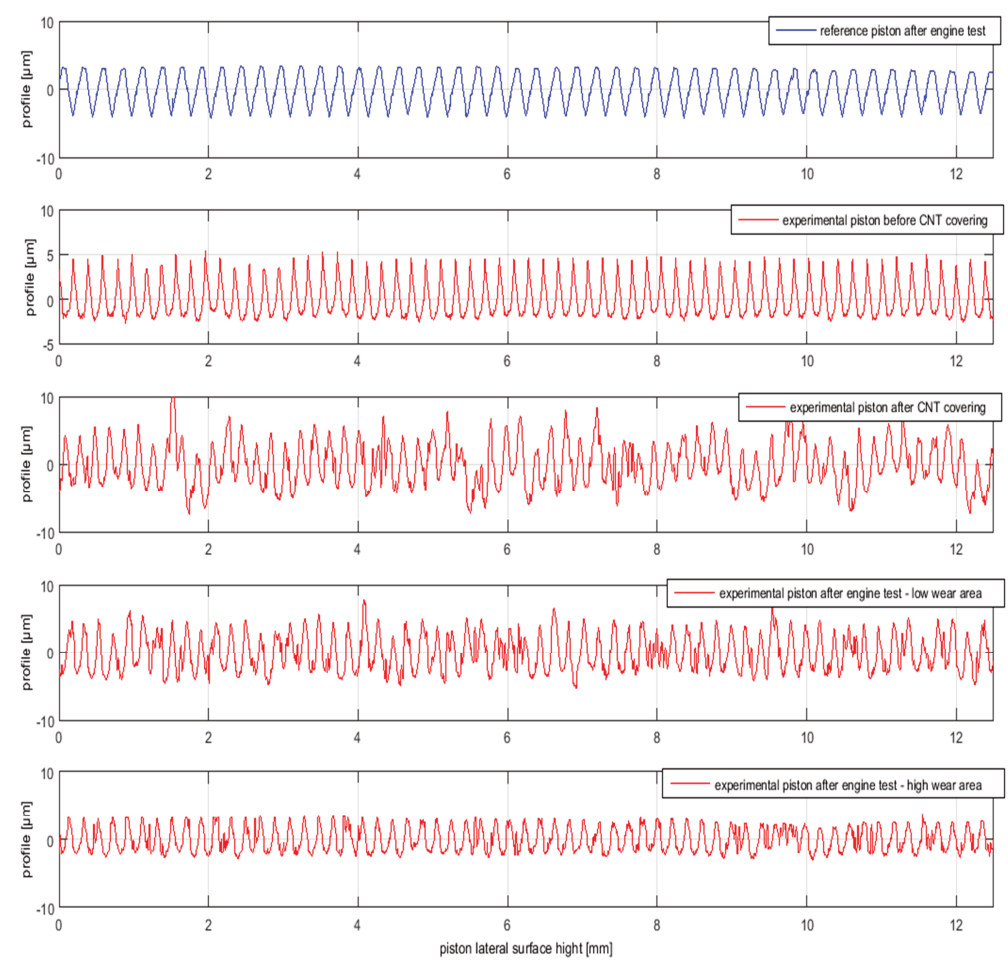

Fig. 7. Selected characteristic profiles of the lateral surface of the pistons used in the friction measurements 
The upper part of Fig. 8 shows the shape of the bearing surface of the piston with a layer of nanotubes. The piston shape is presented, where the horizontal axis represents the perimeter of the piston's bottom side. The lower part of the figure presents the topography of the surface in the same form. The images on the left show the major thrust side of the piston, while the images on the right the minor thrust side. All the data shown relate to piston A3, where the relative values were the same for the second experimental piston. The images show the surface of pistons that were taken out of the engine after the end of the engine tests.
Before mounting the piston and at the end of the engine tests the diameter of the cylinders was measured in 52 cylinder sections. There were no significant signs of wear and the average wear of all sections was $0.8 \mu \mathrm{m}$.

Figure 9 shows the structure of a layer of CNTs on the surface of the experimental piston. This SEM image

was recorded for the piston taken out of the engine at the end of the engine experiment. Before taking the image, the sample was washed in acetone.
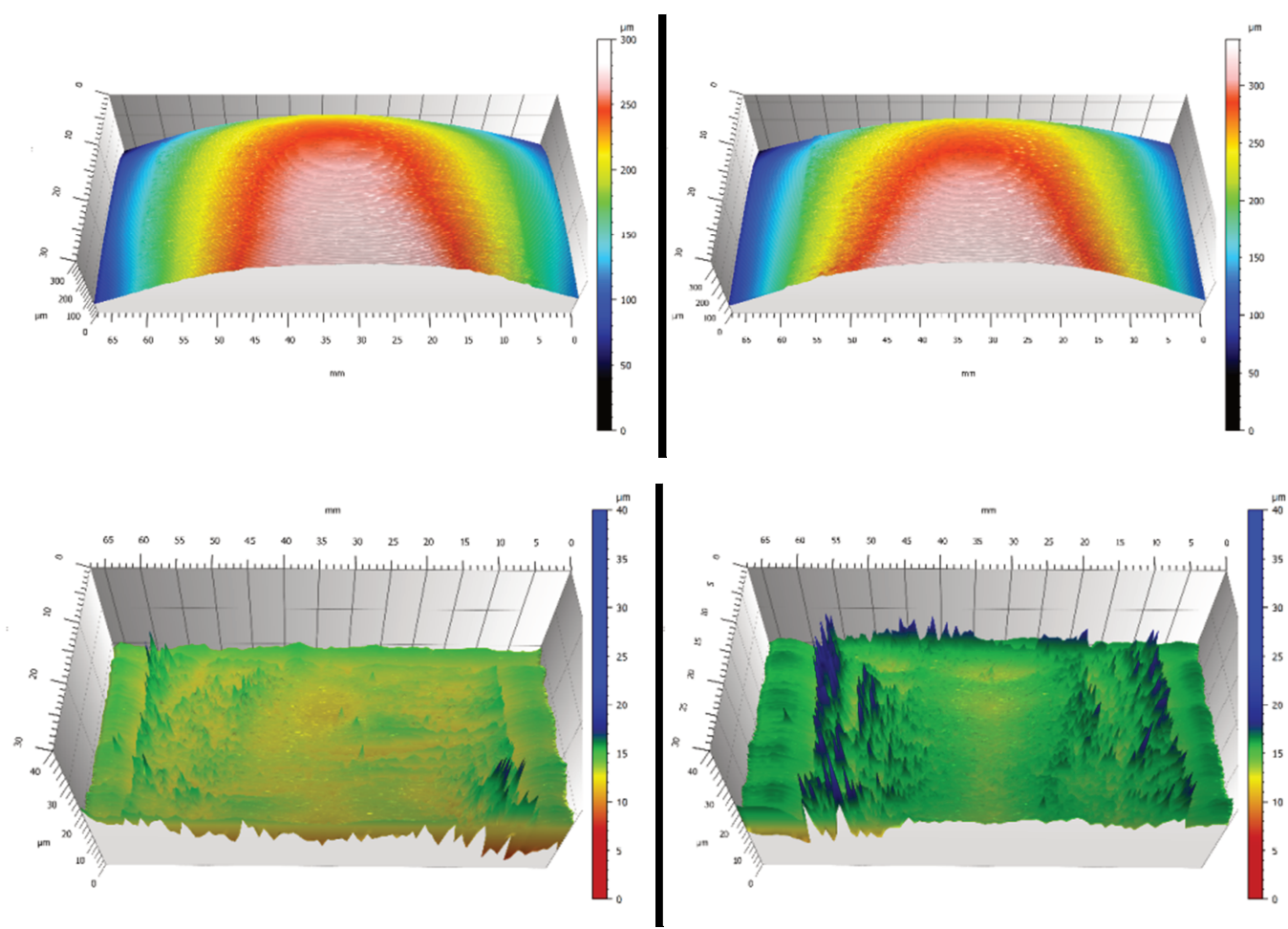

Fig. 8. Piston wear as a result of the engine tests; the bearing surface on the major thrust side shown on the left and minor thrust side on the right; the shape of the bearing surface of the piston coated with nanotubes shown on the top and the surface topography on the bottom

The EDS analysis has found that in addition to carbon, the surface composition also contained aluminum and iron, which are the products of abrasion of friction components. The aluminum alloy also contained silicon; while oxygen and potassium are substances used in the process of applying the CNTs. Spectroscopy results are shown in Fig. 10.
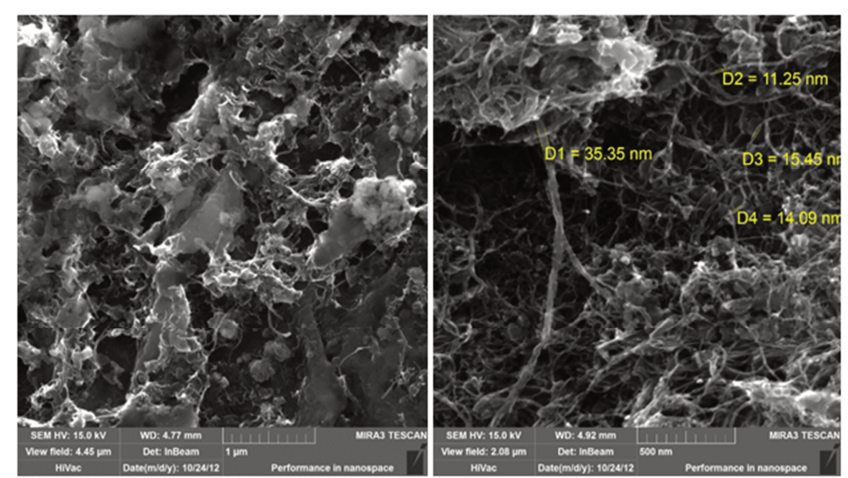

Fig. 9. The surface of the CNTs on the piston; image captured after the completion of the engine tests from a sample washed in acetone
The EDS analysis has found that in addition to carbon, the surface composition also contained aluminum and iron, which are the products of abrasion of friction components. The aluminum alloy also contained silicon; while oxygen and potassium are substances used in the process of applying the CNTs.

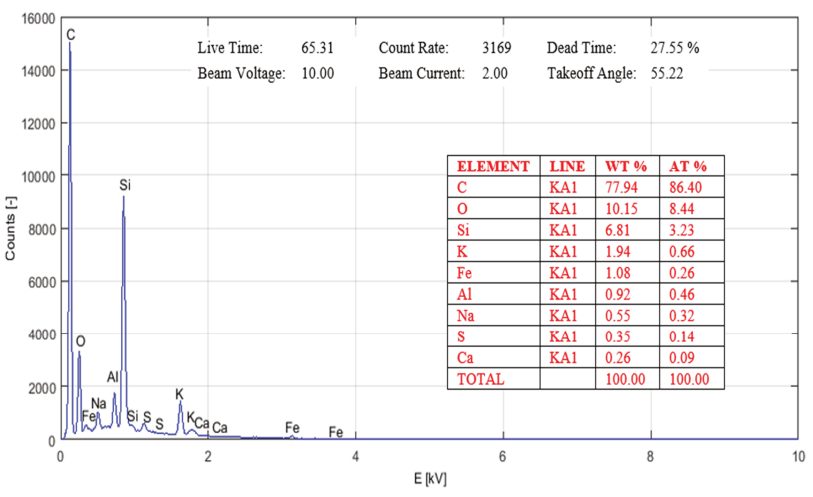

Fig. 10. EDS spectroscopy for the surface of CNT layer on the piston dismounted after completing the engine tests 
A series of experimental studies of pistons was finalized with a computer X-ray tomography of the experimental pistons. CT scan shows the close adhesion of the CNTs to the material of the piston; no presence of any air bubbles was found at the layer border.

\subsection{Ideas for improving the technology for application of carbon nanotubes}

This article presents a spray method of application of CNTs on the piston skirt which is only one of many possible methods. An alternative technique is to use a layer of resins, polymers containing CNTs with proved favorable tribological properties [10, 16, 19, 20, 34, 35, 40, 43]. The use of IG-type CNTs with ferromagnetic catalyst nanoparticles at their ends enables an external electromagnetic field to interact with the CNTs and produce an ordered spatial structure.

The authors have, however, researched the possibility of using another original method based on electrolytic deposition of MWCNTs from an aqueous solution. Suitable prepa- ration of the piston surface, and conducting the CNT deposition process using a periodically reversing current, made it possible to obtain a layer with high adhesion and promising properties. These layers are characterized by a relatively ordered spatial structure (Fig. 11), different from the structures obtained by spraying CNTs onto a surface. Using the piston layer of CNTs obtained by the process of electrodeposition, the anisotropic properties of the CNTs could be taken advantage of in order to reduce friction.

In the long term one can imagine a hierarchical, multilayered structure of CNTs applied on the piston skirt, where each layer would have a specialized function. The layer closest to the piston material would provide high adhesion, then a layer of damping, the next layer with favorable tribological properties, and the contact surface layer would protect a new engine from seizing. It seems likely that the use of nanoparticles of established favorable tribological characteristics (Co, Mo, W) could contribute to the improvement of properties of hierarchical layers based on CNTs.

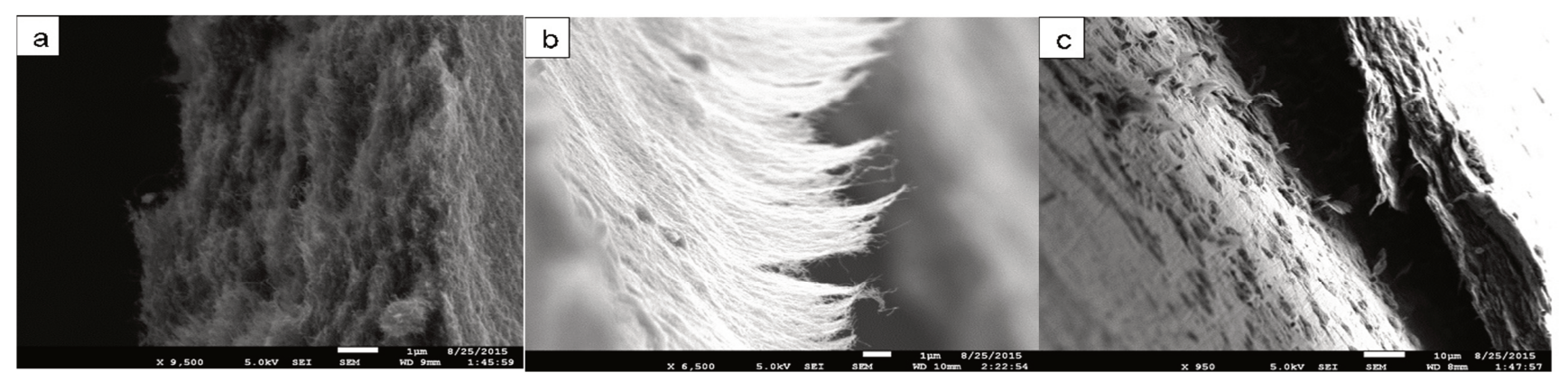

Fig. 11. The layers of CNTs obtained in the process of electrolytic deposition: a) ordered structure of CNTs shown in a cross-section of layers; b) ordered structure of CNTs on the surface of the layer after bending and rupture; c) oxide layer on the metal surface formed by a chemical method significantly enhances the CNT adhesion to the base metal surface (left part of the picture), even if the CNT layer is broken down the metal surface will not be cleaned of CNTs

\section{Analysis of the results}

The analysis of the results was divided into two parts: the main part concerns the results of friction losses, the second part is a supplementary research conducted to better understand the phenomena and processes occurring in the engine and determining friction and wear.

\subsection{Ideas for improving the technology for application of carbon nanotubes}

It should be considered that the recorded engine motoring torque values are determined by the following main components:

a) friction losses occurring between the piston skirt and the cylinder, which are the subject of the analysis in this study

b) friction losses between the piston rings and the cylinder

c) friction losses in the crankshaft bearings

d) the escape of part of the compressed load from the cylinder to the crankcase (blow-by), and thermodynamic losses associated with heating the cylinder walls.

It can be assumed that the layer of CNTs on the piston skirt surface does not substantially affect the processes listed in points b-d. Therefore, comparison of the engine motoring torque registered in the same operating conditions of the engine for the standard pistons and piston coated with CNTs should allow determining the impact of the layer of CNTs on friction losses.

The use of CNTs on the piston skirts resulted in a significant reduction in friction losses, expressed by a decrease in the engine motoring torque, reaching up to $16 \%$ in certain engine operating conditions (Fig. 4). It should be emphasized that the disclosed difference relates to the overall friction losses, which beside the loss at the piston skirt, also consists of friction losses caused by piston rings and bearings of the crankshaft. The test results presented in the literature indicate that all three of these kinematic pairs are comparable in terms of friction losses [32, 33]. Therefore, the reduction of friction losses recorded after installing the experimental pistons, in which only the skirt surface material was changed, is surprisingly high.

It is suspected that such a large reduction in friction losses, observed after mounting the experimental pistons with a CNT layer, should not be attributed solely to friction changes on the piston skirt. Supplementary research has shown that the prototype CNT layer was characterized by rapid wear - during a few hours of research preceded by several hours of engine run-in the CNT layer thickness receded by about $20 \mu \mathrm{m}$ due to wear (see Figs 6 and 8). The ablated CNTs have probably dispersed well in the engine oil, due to the continuity of the process of attrition, and 
could reach all the friction components with the oil circulating in the engine and noticeably reduce the total friction losses.

The study compares the engine friction losses for CNT coated experimental pistons with the corresponding values measured for standard pistons provided by the engine manufacturer, which are aluminum pistons without any additional layers on the side surfaces. The resin containing graphite or molybdenum disulfide substances widely used nowadays to cover pistons may also help to reduce friction losses, but the benefits are incomparably smaller than the values observed in our studies [12, 17, 26, 32].

Engine friction losses under normal operating conditions occur primarily in the hydrodynamic friction regime. The share of the engine friction losses induced in the mixed friction regime, which become particularly noticeable at low engine speed and high engine load is limited in comparison. CNTs present in the oil may reduce friction losses for both the hydrodynamic and mixed friction regimes, the relevant mechanisms (the effects of nanotubes) are discussed in detail in [8]. The study described in this paper shows a clear relation between reducing friction losses resulting from the application of nanotubes and engine speed and load. The higher the engine speed and the lower the engine load, the more pronounced the observable benefits of using nanotubes. This may seem to indicate that CNTs in the oil reduce the friction losses primarily in the hydrodynamic friction regime. However, according to the authors, the reasons for the observed reduction in friction losses relative to the engine speed are much more complex, and may include the mechanisms described in [8]; furthermore, high engine speed promotes better dispersion of nanotubes in the oil circulating in the engine lubrication system.

\subsection{Analysis of supplementary research results}

Testing the shape of the pistons using the coordinate measuring technique was performed for the reference and experimental pistons before and after the engine test. The diameter of the reference pistons measured after completion of the study was $79.998 \mathrm{~mm}$ and the diameter of the experimental pistons dismounted from the engine after the study was $79.990 \mathrm{~mm}$. These values are similar and it can be assumed that the difference of 8 microns did not have a direct impact on the recorded friction losses.

The surface roughness of the reference piston and the run-in experimental piston had similar $\mathrm{Ra}$ values equal to 3.99 microns and 3.75 microns, respectively. A very important condition for ensuring comparability of results of friction losses was therefore satisfied.

The applied layer of CNTs originally had a thickness of about 40 microns (Fig. 6), although the precise value is difficult to determine because of the roughness of the surface of the aluminum piston and the surface roughness of the nanotubes. Similar relationships exist with respect to standard graphite layers and molybdenum.

In the images showing the surface of the pistons taken out of the engine at the end of the study (Fig. 8) the edges of the regions covered with nanotubes are easily visible, mainly as the lines perpendicular to the horizontal axis, intersecting the axis around the coordinates $5 \mathrm{~mm}$ and 60 $\mathrm{mm}$. The images showing the surface topography reveal the character of the wear in CNT layers, where the roughness of the CNT layer surface is visibly reduced in the central part of the piston surface. As expected, the wear process occurred more heavily on the major thrust side of the piston.

The layer of CNTs does undergo wear while the engine operates, which is due to the limited cohesion of the spraycoated CNT layer. SEM images of the CNTs taken on the piston dismounted after the engine tests show, however, that the conditions in the engine do not lead to the destruction of the CNTs.

Comparing the shape of the cylinder measured before and after the piston test does not indicate the existence of significantly accelerated cylinder liner wear; however, the relatively short test cannot replace durability tests. The disassembly of the engine carried out after completing the experimental piston tests did not reveal any worrying signs of accelerated wear in any of the friction components, in particular in the piston assembly and the crankshaft bearings.

Based on the SEM images and the EDS analysis, the ability of CNTs to attach foreign particles onto their surface can be observed. These particles attached during engine running could be called pollution in the technical evaluation of CNT images, but from the tribological point of view they can play a beneficial role. This feature can be used to deliberately decorate the CNTs with nanoparticles which have proven favorable tribological properties.

\section{Conclusions}

A prototype piston with a CNT-coated skirt was prepared and successfully tested for the first time in an engine. The described technique of applying CNT layers enabled the creation of experimental pistons, but it requires improvements in order to enhance the layer durability. Therefore, it is not yet suitable for industrial use. After successful modification of certain details, the proposed technology of applying layers of CNTs can be adapted for use in industrialscale production.

Images of the samples taken at the surface of the piston after engine tests, recorded using a scanning electron microscope (SEM), confirm the survivability of the CNTs and their resistance to the chemical environment and mechanical loads on the piston skirts.

The experimental pistons dismounted from the engine were not significantly different in outer diameter or surface roughness compared to the reference pistons; thus the basic criterion for the comparability of friction losses was fulfilled.

The results of the main part of the study indicate that following the application of CNTs onto experimental pistons, significantly decreased friction losses occurred. The difference in motoring torque of the engine with regular pistons and the CNTs coated pistons reached up to $16 \%$.

On the basis of measurements of piston surface roughness and shape made before and after engine tests a high level of abrasion of the CNTs layer can be observed. However, this problem arises primarily from the type of binder, and not the properties of the CNTs and so this may be easily resolved in the future. 
It is likely that the significant reduction in the engine motoring torque registered in the experiments using pistons coated with CNTs is not solely due to the modification of the contact conditions of the piston with the cylinder. The CNTs are continuously abraded off the surface of the piston and dispersed in the oil where they can then reach all the friction components in the engine. If the described effect indeed appeared during engine operation, it would be possible to use easily replaceable elements to control the release of CNTs into the oil, for example: timing chain guides. This approach would be a good solution to the instability problem of CNT enriched oils.

It has been shown that CNTs do not adversely affect the process of wear of the cylinder liner.

The results of the research on alternative, electrodeposition methods of applying the CNT layers onto the surface of the piston have been presented and a functionally specialized hierarchical CNT multilayer coating was proposed.

ACKNOWLEDGEMENT - The authors would like to thank all those who contributed to the final outcomes presented in the paper, by giving inspiration for the research, supporting laboratory tests, scientific cooperation, development and revision of the article. We are particularly thankful to David Carnahan, the president of NanoLab Inc., the exclusive supplier of the CNTs used in our research. We wish to give special thanks to professors Antoni Iskra and Michał Ciałkowski.

FUNDING - This work was supported by the Polish National Science Centre [N N502 511240], the Institute of Combustion Engines and Transport, Poznan University of Technology, Poland and NanoLab, Inc. Waltham, MA, USA.

\section{Bibliography}

[1] ABAD, M.D., SÁNCHEZ-LÓPEZ, J.C., BERENGUERMURCIA, A. et al. Catalytic growth of carbon nanotubes on stainless steel: characterization and frictional properties. $D i$ amond and Related Materials. 2008, 17(11).

[2] ADAM, A., PREFOT, M., WILHELM, M. Kurbelwellenlager für Motoren mit Start-Stop-System, MTZ. 2010, 12.

[3] ATSUSHI, H., NOBUAKI, Y. Sliding friction properties of carbon nanotube coatings deposited by microwave plasma chemical vapor deposition. Tribology International. 2004, 37(11-12).

[4] BAUGHMAN, R.H., ZAKHIDOV, A.A., DE HEER, W.A. Carbon Nanotubes - the route toward applications. Science. 2002, 787-792.

[5] BHUSHAN, B. Handbook of nanotechnology. SpringerVerlag. Berlin-Heidelberg 2010.

[6] BOSSDORF-ZIMMER, B., KRINKE, S., LÖSCHE-TER, H.T. Die well-to-wheel-Analyse Umwelteigenschaften mess- und planbar Machen. MTZ. 2012, 2.

[7] Carbon nanotubes, www.nano-lab.com.

[8] CHAUVEAU, V. Le pouvoir lubrifiant des nanotubes de carbonne. PhD dissertation. L'Ecole Centrale de Lyon, 2010.

[9] COOK, E.H., BUEHLER, M.J., SPAKOVSZKY, Z.S. Mechanism of friction in rotating carbon nanotube bearings. Journal of the Mechanics and Physics of Solids. 2013, 61, 652-673.

[10] CUI, L.J., GENG, H.Z., WANG, W.Y. et al. Functionalization of multi-wall carbon nanotubes to reduce the coefficient of the friction and improve the wear resistance of multi-wall carbon nanotube/epoxy composites. Carbon. 2013, 54.

[11] DE VOLDER, M.F., TAWFICK, S.H., BAUGHMAN, R.H. et al. Carbon nanotubes: present and future commercial applications. Science. 2013, 339.

[12] DEUSS, T., EHNIS, H., BASSET, M. et al. Reibleistungsmessungen am Befeuerten Dieselmotor - Zyklusrelevante CO2-Ersparnis. MTZ. 2011, 12.

[13] DEUSS, T., EHNIS, H., FREIER, R. et al. Reibleistungsmessungen am Befeuerten Dieselmotor - Potenziale der Kolbengruppe. MTZ. 2010, 5.

[14] DEUSS, T., EHNIS, H., ROSE, R.K. et al. Reibleistungsmessungen am Befeuerten Dieselmotor - Einfluss von Kolbenschaftbeschichtungen. MTZ. 2011, 4.
[15] FENIMORE, A.M., YUZVINSKY, T.D., HAN, W.Q. et al. Rotational actuators based on carbon nanotubes. Nature. 2003, 424.

[16] GOLCHIN, A., WIKNER, A., EMAMI, N. An investigation into tribological behavior of multi-walled carbon nanotube/graphene oxide reinforced UHMWPE in water lubricated contacts. Tribology International. 2016, 95.

[17] GOLLOCH, R. Downsizing bei Verbrennungsmotoren. Springer-Verlag. Berlin-Heidelberg 2005.

[18] HOLMBERG, K., ANDERSSON, P., ERDEMIR, A. Global energy consumption due to friction in passenger cars. Tribology International. 2012, 47.

[19] HUANG, Y.Y., TERENTJEV, E.M. Dispersion of carbon nanotubes: mixing, sonication, stabilization and composite properties. Polymers. 2012, 4.

[20] HWANG, H.J., JUNG, S.L., CHO, K.H. et al. Tribological performance of brake friction materials containing carbon nanotubes. Wear. 2010, 268.

[21] JOHANNE, L.B., YOWELL, L.L., SOSA, E. et al. Survivability of single-walled carbon nanotubes during friction stir processing. Nanotechnology. 2006, 17.

[22] JOLY-POTTUZ, L., DASSENOY, F., VACHER, B. et al. Ultralow friction and wear behavior of $\mathrm{Ni} / \mathrm{Y}$-based single wall carbon nanotubes (SWNTs). Tribology International. 2004, 37.

[23] KAŁUŻNY, J. Experimental applications of carbon nanotubes in the construction of internal combustion engines. Poznan University of Technology Publishing House, Poznan 2013.

[24] KAŁUŻNY J. Wpływ kształtu powierzchni bocznej tłoka na parametry filmu olejowego pokrywającego gładź cylindra. Doctoral dissertation. Poznan 2004.

[25] KASHYAP, K.T., RAHUL, R., YAMDAGNI, S. Strengthening in carbon nanotube/aluminum (CNT/Al) composites. Scripta Materialia. 2005.

[26] KENNEDY, M., HOPPE, S., ESSER, J. Kolbenringbeschichtung zur Reibleistungssenkung im Ottomotor. MTZ. $2012,5$.

[27] LIN, R.M., LU, C. Modeling of interfacial friction damping of carbon nanotube-based nanocomposites. Mechanical Systems and Signal Processing. 2010, 24(8).

[28] LIU, Q., KE, L., LIU, F. et al. Microstructure and mechanical property of multi-walled carbon nanotubes reinforced aluminum matrix composites fabricated by friction stir processing. Materials and Design. 2013, 45. 
[29] LIU, Z.Y., XIAO, B.L., WANG, W.G. et al. Developing high-performance aluminum matrix composites with directionally aligned carbon nanotubes by combining friction stir processing and subsequent rolling. Carbon. 2013, 62.

[30] LU, H. et al. Friction and adhesion properties of vertically aligned multi-walled carbon nanotube arrays and fluoronanodiamond films. Carbon. 2008, 46.

[31] LUCAS, M., PALACI, I., RIEDO, E. et al. Hindered rolling and friction anisotropy in supported carbon nanotubes. $\mathrm{Na}$ ture Materials. 2009, 8.

[32] Mahle GmbH - Piston and engine testing. Stuttgart 2012.

[33] MAUCH, A., TOPHOVEN, J., TRZEBIATOWSKI, T. et al. Potenziale und Grenzen des Downsizing beim Dieselmotor. MTZ. 2011, 7-8.

[34] MENG, H., SUI, G.X., XIE, G.Y. et al. Friction and wear behavior of carbon nanotubes reinforced polyamide $6 \mathrm{com}$ posites under sliding and water lubricated condition. Composites Science and Technology. 2009, 69(5).

[35] OLEK, M., KEMPA, K., JURGA, S. et al. Nanomechanical properties of silica coated multiwall carbon nanotubespoly(methyl methacrylate) composites. Langmuir. 2005, 21.

[36] QIANMING, G., DAN, L., XIAOSU, Y. et al. Tribology of polymeric nanocomposites. Friction and Wear of Bulk Materials and Coatings. 2013.

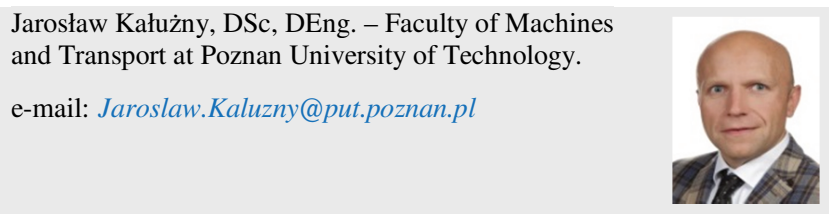

Prof. Jerzy Merkisz, DSc., DEng. - Professor in the Faculty of Machines and Transport at University of Technology.

e-mail: Jerzy.Merkisz@put.poznan.pl

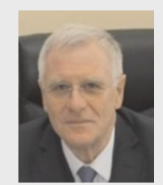

Krzysztof Kempa - Professor of Physics at Boston College, Department of Physics, Boston College.

e-mail:Kris.Kempa@bc.edu

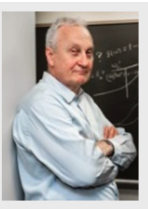

Emil Wróblewski, MEng. - postgraduate in the Faculty of Machines and Transport at Poznan University of Technology.

e-mail:Emil.Z.Wroblewski@doctorate.put.poznan.pl

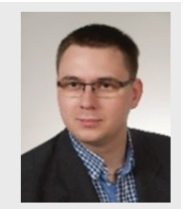

Aleksander Stepanenko, MEng. - postgraduate in the Faculty of Machines and Transport at Poznan University of Technology.

e-mail: Stepanenko@wp.pl.

Mohanad Al-Karawi, MEng. - postgraduate in the Faculty of Machines and Transport at Poznan University of Technology.

e-mail: Mohanad.Al-Karawi@doctorate.put.poznan.pl
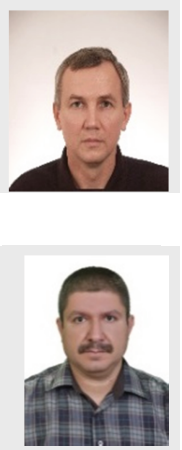

Bartosz Gapiński, DEng. - Faculty of Mechanical Engineering and Management at Poznan University of Technology.

e-mail: Bartosz.Gapinski@put.poznan.pl

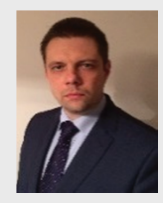

